\title{
BMJ Open Influence of family history on the willingness of outpatients to undergo genetic testing for salt-sensitive hypertension: a cross-sectional study
}

\author{
Taro Takeshima, ${ }^{1}$ Masanobu Okayama, ${ }^{1,2}$ Ryusuke Ae, ${ }^{3}$ Masanori Harada, ${ }^{4}$ \\ Eiji Kajii ${ }^{1}$
}

To cite: Takeshima T, Okayama M, Ae R, et al. Influence of family history on the willingness of outpatients to undergo genetic testing for salt-sensitive hypertension: a cross-sectional study. BMJ Open 2017;7:e016322. doi:10.1136/ bmjopen-2017-016322

- Prepublication history for this paper is available online. To view these files please visit the journal online (http://dx.doi. org/10.1136/bmjopen-2017016322)

Received 7 February 2017

Revised 20 May 2017

Accepted 12 June 2017

\section{CrossMark}

${ }^{1}$ Division of Community and Family Medicine, Center for Community Medicine, Jichi Medical University, Tochigi, Japan

${ }^{2}$ Division of Community

Medicine and Medical

Education, Kobe University, Graduate School of Medicine, Kobe, Japan

${ }^{3}$ Division of Public Health, Center for Community Medicine, Jichi Medical University, Tochigi,

Japan

${ }^{4}$ Department for Support of Rural Medicine, Yamaguchi Grand Medical Center, Yamaguchi, Japan

Correspondence to

Dr Taro Takeshima; taro-tksm@ jichi.ac.jp

\section{ABSTRACT}

Objectives It is unclear whether family medical history influences the willingness to undergo genetic testing. This study aimed to determine how family history affected the willingness to undergo genetic testing for salt-sensitive hypertension in patients with and without hypertension.

Design Cross-sectional study using a self-administered questionnaire.

Setting Six primary care clinics and hospitals in Japan. Participants Consecutive 1705 outpatients aged $>20$ years, 578 of whom had hypertension.

Primary and secondary outcome measures The primary outcome variable was the willingness to undergo genetic testing to determine the risk of salt-sensitive hypertension, and the secondary variables were age, sex, education level, family history and concerns about hypertension. Factors associated with a willingness to undergo genetic testing were evaluated in patients with and without hypertension using a logistic regression model.

Results In the hypertension and non-hypertension groups, $323(55.9 \%)$ and 509 patients (45.2\%), respectively, were willing to undergo genetic testing. This willingness was related with a high level of education (adjusted OR (ad-OR): $1.81,95 \% \mathrm{Cl} 1.12$ to 2.93$)$, family history of stroke (1.55, 1.04 to 2.31 ) and concerns about hypertension (2.04, 1.27 to 3.28 ) in the hypertension group, whereas in the non-hypertension group, it was influenced by education level (ad-OR: $1.45,95 \% \mathrm{Cl} 1.13$ to 1.86$)$, family history of hypertension (1.52, 1.17 to 1.98$)$ and concerns about hypertension (2.03, 1.53 to 2.68$)$.

Conclusions The influence of family history on the willingness to undergo genetic testing for risk of saltsensitivity hypertension differed between participants with and without hypertension. In particular, participants without hypertension wished to know their likelihood of developing hypertension, whereas those with hypertension were interested to know the risk of stroke (a complication of hypertension). Family history could help better counsel patients about genetic testing on the basis of their medical history.

\section{INTRODUCTION}

Family history is the most important tool in diagnosing and assessing risk in medical

\section{Strengths and limitations of this study}

- Logistic regression analyses were performed to examine the associations between family history and willingness to undergo genetic testing in patients with and without hypertension.

- The generalisability of the results may not extend to non-Japanese populations.

- This study used self-reported data, which might have introduced information bias.

- Unidentified confounding factors may have affected the association between the willingness to undergo genetic testing and family medical history.

genetics, and it serves as a critical element in the use of predictive genetic testing in primary care. ${ }^{1}$ In particular, a family history of hypertension is significantly associated with primary hypertension. ${ }^{2-4}$ Although knowledge of patient genetics is useful in making decisions regarding treatment, patients are often ill prepared for such tests. ${ }^{5}$ Nevertheless, when patients with chronic disease seek information on their genetics or genetic testing, their general practitioner should provide such information. ${ }^{5}$

The recent completion of the human genome project and the current research on single nucleotide polymorphisms led to the identification of genetic mutations that increase the risk of common diseases such as cardiovascular disease, diabetes and cancer. ${ }^{6}$ Moreover, direct-to-consumer genetic testing services provided by private companies are rapidly gaining popularity. ${ }^{7}$ However, consumers have concerns regarding possible adverse consequences of genetic testing, particularly privacy issues and discrimination in health insurance and employment. ${ }^{8}$ Furthermore, because the clinical outcome of genomic medicine interventions for common chronic diseases is still unclear, 
physicians also have misgivings regarding genetic testing and seem reluctant to recommend it. ${ }^{8}$ Typically, prospective users are worried about the onset of diseases such as breast cancer and ovarian cancer. ${ }^{910}$ Genetic testing has merits and demerits in this regard; despite the predictive capability, it is limited in terms of clinical validity and has unknown clinical utility. ${ }^{11} 12$ The prerequisites of the use of genetic testing for primary care include understanding the current limitations of this approach and possible consequences of its commercial over-the-counter application; the primary care team may identify those who they believe will benefit from further discussion about their family history. ${ }^{13}$

Several gene polymorphisms associated with salt-sensitive hypertension have been identified. ${ }^{14-16}$ Patients with these genetic factors are likely to develop hypertension from excessive salt intake. ${ }^{14}$ Moreover, hypertension is a risk factor for stroke and myocardial infarction. ${ }^{17-19}$ We previously reported that family history of hypertension was an independent factor positively related to the willingness of outpatients to undergo genetic testing for salt-sensitive hypertension. ${ }^{20}$ However, the effects of family history might differ in patients with and without hypertension. In this study, we evaluated the association between family history and willingness to undergo genetic testing for salt-sensitive hypertension in patients with and without hypertension; we expect that the results of this study could help respond to the misgivings of physicians and help them to deal appropriately with family history information during genetic counselling.

\section{METHODS}

\section{Study design}

This was a cross-sectional study that used a self-administered questionnaire.

\section{Participants and settings}

We enrolled consecutive outpatients aged $>20$ years who visited the primary care departments of four clinics and two small hospitals in Japan.

\section{Measurements}

We collected data during 2-week periods at each clinic or hospital between September 2009 and February 2010. The patients received the questionnaire from research assistants at reception and answered it in the waiting room after being informed that they could decline participation without incurring any penalty and that they would not be remunerated for participation. Whether patients answered the questionnaire was not revealed to the primary care physicians. The questionnaire included questions on the patient's age, sex, education level, family and personal medical history (with regard to hypertension, diabetes mellitus, stroke and myocardial infarction), body mass index (BMI), concerns pertaining to hypertension and diabetes mellitus ('Do you worry about developing hypertension?' and 'Do you worry about developing diabetes mellitus?', respectively), salt preferences
('Do you prefer salty foods?'), current lifestyle (smoking, drinking, regular exercise and reduced salt intake) and willingness to undergo genetic testing for salt-sensitive hypertension ('Would you prefer to undergo a genetic test to determine whether you are genetically predisposed to hypertension due to excessive salt intake?'). We provided a description of the genetic test for salt-sensitive hypertension ('This test examines the presence of the salt-sensitive gene that tends to cause salt retention in the body, leading to hypertension.') but no additional information.

\section{Statistical analysis}

We divided the participants into two groups, with and without hypertension, based on the presence of hypertension in the self-reported medical history. Before descriptive analysis, participants were divided into three categories by age $(<50,50-64$ and $\geq 65$ years $)$. Obesity was defined as a BMI $>25 \mathrm{~kg} / \mathrm{m}^{2}$, according to the criteria of obesity in Japan and Asia-Oceania. ${ }^{21}$ Continuous data for age are expressed as mean $\pm \mathrm{SD}$, and categorical data for all other variables are expressed as proportions. For testing, t-tests and $\chi^{2}$ tests were used to compare age and proportions of participants between the groups with and without hypertension, respectively.

Logistic regression analyses were conducted to determine factors related to the willingness to undergo genetic testing for each patient. For these analyses, the patients were divided dichotomously in two groups on the basis of age ( $\geq 50$ years and $<50$ years). Patients who had graduated from a college or university were classified into the higher education group, while all others were classified into the non-higher education group. In univariate analysis, crude ORs and 95\% CIs were calculated for age, sex, education level, occupation, family medical history, personal medical history, obesity, concerns about hypertension and diabetes mellitus and salt preferences. Adjusted ORs (ad-ORs; 95\% CI) were then calculated by adjusting for variables that were significantly associated in the univariate analyses. The significance threshold was set at 0.05 . Statistical analysis was performed using STATA/ SE, V.11.2.

\section{Ethics}

The Bioethics Committee of Jichi Medical University approved this study.

\section{RESULTS}

Of the 2237 outpatients, 1705 (76.2\% response rate) completed the questionnaire and were included in the study. Mean age of all participants was $57.5 \pm 17.6$ years (males: 607; 35.6\%). The numbers of participants with and without hypertension were $578(33.9 \%)$ and 1127 $(66.1 \%)$, respectively; $323(55.9 \%)$ participants with hypertension and 509 (45.2\%) participants without hypertension were willing to undergo genetic testing. The mean age differed between the two groups (with hypertension: $69.6 \pm 12.4$ years; without hypertension: 
Table 1 Characteristics of participants who completed the questionnaire $(n=1705)$

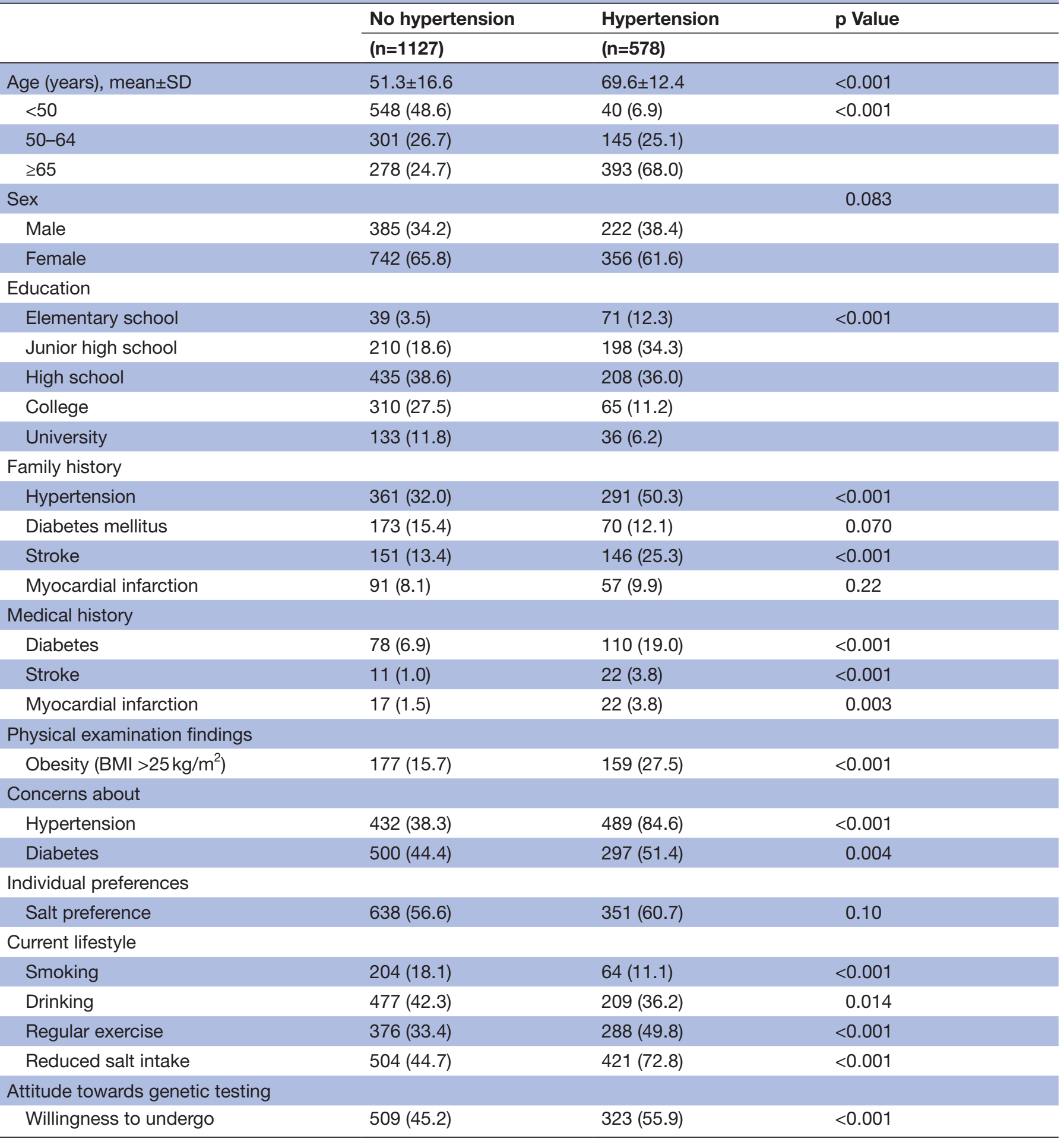

Data are presented as $\mathrm{N}(\%)$ or mean \pm SD.

BMI, body mass index.

$51.3 \pm 16.6$ years). Similarly, the proportions with and without hypertension differed according to age; education level; family history of hypertension and stroke; medical history of diabetes, stroke and myocardial infarction; presence of obesity; concerns about hypertension and diabetes; current smoking and drinking; regular exercise; reduced salt intake; and desire to undergo a genetic test differed significantly between the groups (table 1).

In the univariate analysis, the factors associated with a willingness to undergo genetic testing for participants without hypertension were higher education (crude OR, 
Table 2 Univariate analysis of associations between measured variables and willingness to undergo a genetic test in patients without hypertension

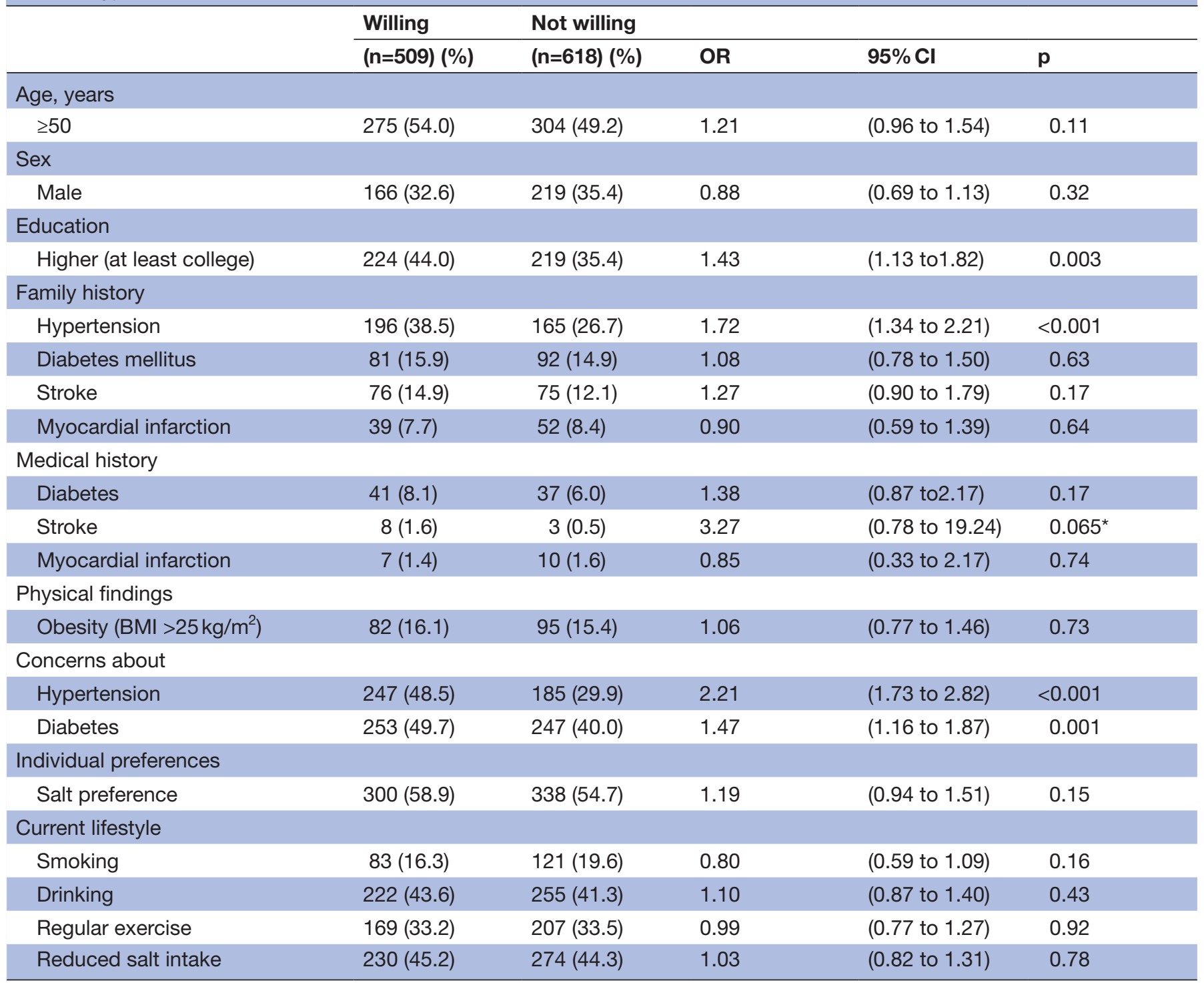

${ }^{*}$ Fisher's exact test.

BMI, body mass index.

1.43 ; $95 \%$ CI 1.13 to 1.82$)$, a family history of hypertension (crude OR: $1.72 ; 95 \%$ CI 1.34 to 2.21 ) and concerns about hypertension (crude OR, 2.21;95\% CI 1.73 to 2.82 ) or diabetes mellitus (crude OR, 1.47; 95\% CI 1.16 to 1.87 ) (table 2).

In participants with hypertension, such factors were higher education (crude OR, 2.11; 95\% CI 1.33 to 3.35), a family history of hypertension (crude OR, 1.50; 95\% CI 1.08 to 2.09 ) or stroke (crude OR, $1.60 ; 95 \%$ CI 1.09 to 2.36) and concerns about hypertension (crude OR, 2.34; 95\% CI 1.47 to 3.71) (table 3).

Multivariate logistic regression analysis (table 4) revealed that higher education (ad-OR, 1.45; 95\% CI 1.13 to 1.86 ), a family history of hypertension (ad-OR, 1.52; 95\% CI 1.17 to 1.98 ) and concerns about hypertension (ad-OR, 2.03; 95\% CI 1.53 to 2.68) were the factors independently associated with the willingness to undergo genetic testing in participants without hypertension, whereas in those with hypertension such factors were higher education (ad-OR, 1.81; 95\% CI 1.12 to 2.93), a family history of stroke (ad-OR: 1.55; 95\% CI 1.04 to 2.31) and concerns about hypertension (ad-OR, 2.04; 95\% CI 1.27 to 3.28 ).

\section{DISCUSSION}

This study shows that a willingness to undergo genetic testing is affected by family history of stroke and hypertension in individuals with and without hypertension, respectively, demonstrating a difference in the motivation to undergo genetic testing for salt-sensitive hypertension between these two groups. Furthermore, we found that the extent of distress regarding developing an illness depends on the present stage of the disease. Physicians 
Table 3 Univariate analyses of associations between measured variables and willingness to undergo a genetic test in patients with hypertension

\begin{tabular}{|c|c|c|c|c|c|}
\hline & Willingness & No willingne & & & \\
\hline & $(n=323)(\%)$ & $(n=255)(\%)$ & OR & $95 \% \mathrm{Cl}$ & p \\
\hline Age, years & & & & & \\
\hline$\geq 50$ & 299 (92.6) & 239 (93.7) & 0.83 & (0.44 to 1.59$)$ & 0.59 \\
\hline Sex & & & & & \\
\hline Male & $125(38.7)$ & $97(38.0)$ & 1.03 & (0.73 to 1.44$)$ & 0.87 \\
\hline Education & & & & & \\
\hline Higher (at least college) & $71(22.0)$ & $30(11.8)$ & 2.11 & (1.33 to 3.35$)$ & 0.001 \\
\hline Family history & & & & & \\
\hline Hypertension & $177(54.8)$ & $114(44.7)$ & 1.50 & (1.08 to 2.09$)$ & 0.016 \\
\hline Diabetes mellitus & $39(12.1)$ & $31(12.2)$ & 0.99 & (0.60 to 1.64$)$ & 0.98 \\
\hline Stroke & $94(29.1)$ & $52(20.4)$ & 1.60 & (1.09 to 2.36$)$ & 0.017 \\
\hline Myocardial infarction & $35(10.8)$ & $22(8.6)$ & 1.29 & (0.74 to 2.24$)$ & 0.38 \\
\hline Medical history & & & & & \\
\hline Diabetes & $56(17.3)$ & $54(21.2)$ & 0.78 & (0.52 to 1.18$)$ & 0.24 \\
\hline Stroke & $13(4.0)$ & $9(3.5)$ & 1.15 & (0.49 to 2.66$)$ & 0.76 \\
\hline Myocardial infarction & $13(4.0)$ & $9(3.5)$ & 1.15 & (0.49 to 2.66$)$ & 0.76 \\
\hline Physical findings & & & & & \\
\hline Obesity $\left(\mathrm{BMI}>25 \mathrm{~kg} / \mathrm{m}^{2}\right)$ & $95(29.4)$ & $64(25.1)$ & 1.24 & (0.86 to 1.80$)$ & 0.25 \\
\hline Concerns about & & & & & \\
\hline Hypertension & $289(89.5)$ & $200(78.4)$ & 2.34 & (1.47 to 3.71$)$ & $<0.001$ \\
\hline Diabetes & $176(54.5)$ & $121(47.5)$ & 1.33 & (0.95 to 1.84$)$ & 0.097 \\
\hline Individual preferences & & & & & \\
\hline Salt preference & $206(63.8)$ & $145(56.9)$ & 1.34 & (0.95 to 1.87$)$ & 0.15 \\
\hline Current lifestyle & & & & & \\
\hline Smoking & $39(12.1)$ & $25(9.8)$ & 1.26 & (0.75 to 2.14 ) & 0.39 \\
\hline Drinking & 118 (36.5); & $91(35.7)$ & 1.04 & (0.74 to 1.46$)$ & 0.83 \\
\hline Regular exercise & $159(49.2)$ & $129(50.6)$ & 0.95 & (0.68 to 1.31$)$ & 0.75 \\
\hline Reduced salt intake & $236(73.1)$ & $185(72.5)$ & 1.03 & (0.71 to 1.48$)$ & 0.89 \\
\hline
\end{tabular}

BMI, body mass index.

Table 4 Multivariate analysis of associations between family history and willingness to undergo genetic testing

\section{Participants without hypertension}

Ad-OR $\quad 95 \% \mathrm{Cl} \quad \mathrm{p}$

Education

Higher (at least college)

1.45

Family history

Hypertension

Stroke

1.52

Concerns about

\begin{tabular}{lcccccc} 
Hypertension & 2.03 & $(1.53-2.68)$ & $<0.001$ & 2.04 & (1.27 to 3.28) & 0.003 \\
Diabetes & 1.10 & $(0.83-1.44)$ & 0.51 & & & \\
\hline
\end{tabular}

Bold font indicates significantly different between groups.

Ad-OR, adjusted OR.

\section{Participants with hypertension}

Ad-OR $\quad 95 \% \mathrm{Cl} \quad$ p

$(1.13-1.86) \quad 0.003$

1.81

(1.12 to 2.93$)$

0.015

$\begin{array}{lllll}\text { (1.17-1.98) } & \mathbf{0 . 0 0 1} & 1.25 & (0.88 \text { to } 1.76) & 0.21\end{array}$

$1.55 \quad(1.04$ to 2.31$) \quad 0.031$


should be aware of this dependence and should provide care accordingly.

Higher education and anxiety related to hypertension were independently associated with a willingness to undergo genetic testing irrespective of the presence of hypertension. Similarly, a previous study demonstrated that people with college or graduate education had higher awareness of the breast cancer genes BRCA1 and BRCA2 and of tests for these genes. ${ }^{22}$ Furthermore, higher knowledge level and education showed significant positive correlations with interest in and awareness of breast cancer and ovarian cancer genetic testing. ${ }^{23} 24$ Higher education (postcollege education) is also significantly associated with concerns related with consumer genetic testing. ${ }^{25}$ Similar to a previous study demonstrating that worry about bowel cancer was a significant factor motivating patients to undergo DNA tests for colorectal cancer, ${ }^{26}$ our study revealed that concerns related to hypertension were significantly associated with the willingness to undergo genetic testing. These results suggest that higher education and a higher level of related anxiety increase the willingness to undergo genetic testing. Higher education does not always lead to better understanding of the disease $\mathrm{e}^{27}$ but may help to more easily understand the limitations of genetic testing. In contrast, those with hypertension seem to have better understanding of the disease because they make efforts to reduce salt intake, stop smoking, refrain from alcohol and engage in regular exercise more than those without hypertension (table 1). Therefore, physicians should consider the extent of a patient's awareness and distress when disclosing the results of genetic tests for salt-sensitive hypertension.

Family history of hypertension was associated with a willingness to undergo genetic testing in patients without hypertension. A previous study reported a similar result; women with a family history of breast cancer had a very high interest in genetic testing for BRCA1 and BRCA2 mutations. ${ }^{9}$ Family history of ovarian cancer also motivated patients to become aware of genetic testing such as that for BRCA. ${ }^{10}$ Fortunately, salt restriction reduces blood pressure and prevents cardiovascular events. ${ }^{28} 29$ Therefore, primary care physicians should emphasise the importance of salt restriction when introducing methods for prevention of hypertension to patients.

Family history of stroke was associated with a willingness to undergo genetic testing in patients with hypertension. In previous studies, we did not find evidence supporting an association between genetic predisposition and the onset of the disease for which genetic testing was performed. Hypertension is a well-known risk factor for stroke. ${ }^{17}$ Accordingly, such patients worry about the possibility of stroke in the future. In contrast, although hypertension is also a risk factor for myocardial infarction, ${ }^{18}$ there was no significant association between family history of myocardial infarction and willingness to undergo genetic testing in this study. In this regard, the incidence of stroke in Japan is four times higher than that of myocardial infarction. ${ }^{30-32}$ Hence, patients might be more concerned about stroke than about myocardial infarction. Primary care physicians should take into account possible anxiety about the risk of stroke, while counselling patients with hypertension and should not emphasise on only risk of stroke due to the salt-sensitive hypertension. A population-based nationwide campaign might help to successfully reduce dietary sodium intake and prevent cardiovascular events. ${ }^{33}$

There are several limitations to this study. First, since all the participants were Japanese, the generalisability of the results may not extend to non-Japanese populations. Mortality from myocardial infarction or stroke differ between populations ${ }^{1734}$; the cumulative mortality from heart diseases is lower in Japan than in the USA and other Western countries. ${ }^{30}$ Family history of myocardial infarction might be associated with a willingness to undergo genetic testing in countries with a high incidence of myocardial infarction. Actually, a population-based survey in the UK showed that respondents with a family history of heart disease were more interested in genetic testing for heart disease than those without. ${ }^{35}$ Further studies should be conducted to verify this. Second, this study used self-reported data, which might have introduced information bias. For example, it is possible that family history was not correctly reported by less educated patients. Patients are often not well informed about family medical history, and the use of family history in adult primary care has been limited owing to multiple substantive barriers. ${ }^{1}$ Third, the patient characteristics used in this study were selected on the basis of previous studies that identified factors associated with a willingness to undergo genetic testing. ${ }^{24}{ }^{36-38}$ However, unidentified confounding factors may have affected the association between a willingness of undergo genetic testing and family medical history.

\section{CONCLUSIONS}

The effect of family history on the willingness to undergo genetic testing for salt-sensitive hypertension depended on whether the individual already had hypertension. Thus, participants without hypertension wished to know the likelihood of developing hypertension in the future, whereas participants with hypertension were interested in knowing their risk of stroke (a complication of hypertension). Family history may be useful when counselling patients about genetic testing on the basis of their medical history.

Acknowledgements We thank S. Fujiwara, MD, PhD; D. Matsuhima, MD, PhD; K. Nakayasu, MD; C. Ishida, MD; Y. Ishibashi, MD; S. Ohguri; R. Kobayashi; and K. Kawabata for their assistance with data collection.

Contributors Conceived and designed the experiments: TT, M0, RA and EK. Performed the experiments: TT, MO and MH. Analysed the data: TT and MO. Contributed reagents/materials/analysis tools: TT, M0 and RA. Wrote the manuscripts: TT, MO and EK.

Funding This study was supported by the Japan Society for the Promotion of Science (Grant Number 21390168).

Competing interests None declared. 
Ethics approval The Bioethics Committee of Jichi Medical University.

Provenance and peer review Not commissioned; externally peer reviewed.

Data sharing statement All available data can be obtained by contacting the corresponding author.

Open Access This is an Open Access article distributed in accordance with the Creative Commons Attribution Non Commercial (CC BY-NC 4.0) license, which permits others to distribute, remix, adapt, build upon this work non-commercially, and license their derivative works on different terms, provided the original work is properly cited and the use is non-commercial. See: http://creativecommons.org/ licenses/by-nc/4.0/

(c) Article author(s) (or their employer(s) unless otherwise stated in the text of the article) 2017. All rights reserved. No commercial use is permitted unless otherwise expressly granted.

\section{REFERENCES}

1. Rich EC, Burke W, Heaton CJ, et al. Reconsidering the family history in primary care. J Gen Intern Med 2004;19:273-80.

2. Barlassina C , et al. Genetics of Essential Hypertension: From Families to Genes. Journal of the American Society of Nephrology 2002:13:155S-64.

3. Liu M, He Y, Jiang B, et al. Association Between Family History and Hypertension Among Chinese Elderly. Medicine 2015;94:e2226.

4. Ranasinghe P, Cooray DN, Jayawardena R, et al. The influence of family history of Hypertension on disease prevalence and associated metabolic risk factors among Sri Lankan adults. BMC Public Health 2015;15:57-6.

5. Morren M, Rijken M, Baanders AN, et al. Perceived genetic knowledge, attitudes towards genetic testing, and the relationship between these among patients with a chronic disease. Patient Educ Couns 2007;65:197-204.

6. Emery J, Hayflick S. The challenge of integrating genetic medicine into primary care. BMJ 2001;322:1027-30.

7. Borry P, Cornel MC, Howard HC. Where are you going, where have you been: a recent history of the direct-to-consumer genetic testing market. J Community Genet 2010;1:101-6.

8. Scheuner MT, Sieverding P, Shekelle PG. Delivery of genomic medicine for common chronic adult diseases: a systematic review. JAMA 2008;299:1320-34.

9. Hutson SP. Attitudes and psychological impact of genetic testing, genetic counseling, and breast cancer risk assessment among women at increased risk. Oncol Nurs Forum 2003;30:241-6.

10. Metcalfe KA, Fan I, McLaughlin J, et al. Uptake of clinical genetic testing for ovarian cancer in Ontario: a population-based study. Gynecol Oncol 2009;112:68-72.

11. Bellcross CA, Page PZ, Meaney-Delman D. Direct-to-consumer personal genome testing and cancer risk prediction. Cancer $J$ 2012;18:293-302.

12. Offit K. Genomic profiles for disease risk: predictive or premature? JAMA 2008;299:1353-5.

13. Rafi I, Qureshi N, Lucassen A, et al. 'Over-the-counter' genetic testing: what does it really mean for primary care? $\mathrm{Br} J$ Gen Pract 2009;59:283-7.

14. Katsuya T, Ishikawa K, Sugimoto K, et al. Salt sensitivity of Japanese from the viewpoint of gene polymorphism. Hypertens Res 2003;26:521-5.

15. Bagos PG, Elefsinioti AL, Nikolopoulos GK, et al. The GNB3 C825T polymorphism and essential hypertension: a meta-analysis of 34 studies including 14,094 cases and 17,760 controls. J Hypertens 2007; $25: 487-500$.

16. Pereira TV, Nunes AC, Rudnicki M, et al. Meta-analysis of the association of 4 angiotensinogen polymorphisms with essential hypertension: a role beyond M235T? Hypertension 2008;51:778-83.

17. Stegmayr B, Asplund K, Kuulasmaa K, et al. Stroke incidence and mortality correlated to stroke risk factors in the WHO
MONICA Project. An ecological study of 18 populations. Stroke 1997:28:1367-74.

18. Pedrinelli R, Ballo P, Fiorentini C, et al. Hypertension and acute myocardial infarction: an overview. J Cardiovasc Med 2012;13:194-202.

19. Lida M, Ueda K, Okayama A, et al. Impact of elevated blood pressure on mortality from all causes, cardiovascular diseases, heart disease and stroke among Japanese: 14 year follow-up of randomly selected population from Japanese -- Nippon data 80. J Hum Hypertens 2003;17:851-7.

20. Okayama M, Takeshima T, Ae R, et al. Primary care patient willingness for genetic testing for salt-sensitive hypertension: a cross sectional study. BMC Fam Pract 2013;14:149.

21. Kanazawa M, Yoshiike N, Osaka T, et al. Criteria and classification of obesity in Japan and Asia-Oceania. World Rev Nutr Diet 2005;94:1-12.

22. Mogilner A, Otten M, Cunningham JD, et al. Awareness and attitudes concerning BRCA gene testing. Ann Surg Oncol 1998;5:607-12.

23. Amin TT, Al-Wadaani HA, Al-Quaimi MM, et al. Saudi women's interest in breast cancer gene testing: possible influence of awareness, perceived risk and socio-demographic factors. Asian Pac $J$ Cancer Prev 2012;13:3879-87.

24. Lacour RA, Daniels MS, Westin SN, et al. What women with ovarian cancer think and know about genetic testing. Gynecol Oncol 2008;111:132-6.

25. Bloss CS, Darst BF, Topol EJ, et al. Direct-to-consumer personalized genomic testing. Hum Mol Genet 2011;20:R132-R141.

26. Collins V, Halliday J, Warren R, et al. Cancer worries, risk perceptions and associations with interest in DNA testing and clinic satisfaction in a familial colorectal cancer clinic. Clin Genet 2000;58:460-8.

27. Haga SB, Barry WT, Mills R, et al. Public knowledge of and attitudes toward genetics and genetic testing. Genet Test Mol Biomarkers 2013;17:327-35.

28. Sacks FM, Svetkey LP, Vollmer WM, et al. Effects on blood pressure of reduced dietary sodium and the Dietary Approaches to Stop Hypertension (DASH) diet. DASH-Sodium Collaborative Research Group. N Engl J Med 2001;344:3-10.

29. Bibbins-Domingo K, Chertow GM, Coxson PG, et al. Projected effect of dietary salt reductions on future cardiovascular disease. $N$ Engl $J$ Med 2010;362:590-9.

30. Ueshima H. Explanation for the Japanese paradox: prevention of increase in coronary heart disease and reduction in stroke. $J$ Atheroscler Thromb 2007:14:278-86.

31. Kitamura A, Sato S, Kiyama M, et al. Trends in the incidence of coronary heart disease and stroke and their risk factors in Japan, 1964 to 2003: the Akita-Osaka study. J Am Coll Cardiol 2008;52:71-9.

32. Kimura $\mathrm{Y}$, Takishita $\mathrm{S}$, Muratani $\mathrm{H}$, et al. Demographic study of firstever stroke and acute myocardial infarction in Okinawa, Japan. Intern Med 1998;37:736-45.

33. Campbell NR, Willis KJ, L'Abbe M, et al. Canadian initiatives to prevent hypertension by reducing dietary sodium. Nutrients 2011;3:756-64.

34. Tunstall-Pedoe H, Kuulasmaa K, Amouyel P, et al. Myocardial infarction and coronary deaths in the World Health Organization MONICA Project. Registration procedures, event rates, and casefatality rates in 38 populations from 21 countries in four continents. Circulation 1994:90:583-612.

35. Sanderson SC, Wardle J, Jarvis MJ, et al. Public interest in genetic testing for susceptibility to heart disease and cancer: a populationbased survey in the UK. Prev Med 2004;39:458-64.

36. Tambor ES, Rimer BK, Strigo TS. Genetic testing for breast cancer susceptibility: awareness and interest among women in the general population. Am J Med Genet 1997;68:43-9.

37. Bunn JY, Bosompra K, Ashikaga T, et al. Factors influencing intention to obtain a genetic test for colon cancer risk: a population-based study. Prev Med 2002;34:567-77.

38. Doukas DJ, Localio AR, Li Y. Attitudes and beliefs concerning prostate cancer genetic screening. Clin Genet 2004;66:445-51. 